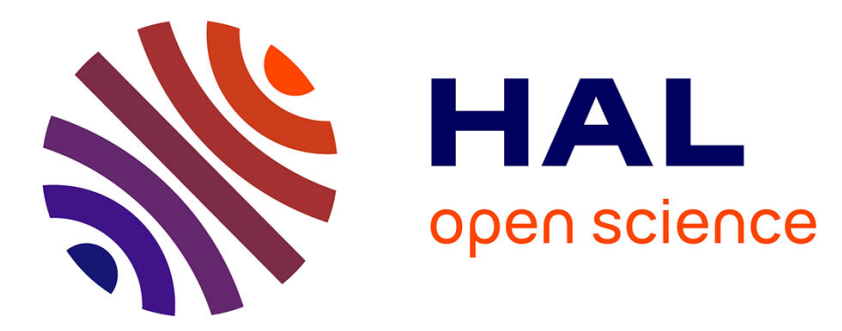

\title{
TEMPORAL EVOLUTION OF SKELETAL REGENERATED TISSUE: WHAT CAN MECHANICAL INVESTIGATION ADD TO BIOLOGICAL?
}

Remy Casanova, Didier Mokoko, Martine Pithioux, Cyril Pailler-Mattéi, Hassan Zahouani, Patrick Chabrand

\section{To cite this version:}

Remy Casanova, Didier Mokoko, Martine Pithioux, Cyril Pailler-Mattéi, Hassan Zahouani, et al.. TEMPORAL EVOLUTION OF SKELETAL REGENERATED TISSUE: WHAT CAN MECHANICAL INVESTIGATION ADD TO BIOLOGICAL?. 2010. hal-00497028

\author{
HAL Id: hal-00497028 \\ https://hal.science/hal-00497028
}

Preprint submitted on 2 Jul 2010

HAL is a multi-disciplinary open access archive for the deposit and dissemination of scientific research documents, whether they are published or not. The documents may come from teaching and research institutions in France or abroad, or from public or private research centers.
L'archive ouverte pluridisciplinaire HAL, est destinée au dépôt et à la diffusion de documents scientifiques de niveau recherche, publiés ou non, émanant des établissements d'enseignement et de recherche français ou étrangers, des laboratoires publics ou privés. 
Editorial Manager(tm) for Medical \& Biological Engineering \& Computing Manuscript Draft

Manuscript Number: MBEC1939R2

Title: WHAT CAN MECHANICAL INVESTIGATION ADD TO BIOLOGICAL? TEMPORAL EVOLUTION OF SKELETAL REGENERATED TISSUE.

Article Type: Original article

Keywords: bone regeneration, large volume, indentation test, histology

Corresponding Author: Dr martine pithioux, $\mathrm{PhD}$

Corresponding Author's Institution: Institute of Movement Sciences

First Author: remy Casanova, PHd

Order of Authors: remy Casanova, PHd; didier Moukoko, PHd, MD; martine pithioux, PhD; Cyril PaillerMattéi , PHd; hassan Zahouani, PUPH; patrick Chabrand, PUPH

Abstract: The objective here was to experimentally characterise the temporal evolution of the structural and mechanical properties of large volume immature regenerated tissues. We studied these evolving tissues from their genesis in controlled mechanical conditions. We developed an animal model based on the periosteal properties leading to unloaded regenerated skeletal tissue. To characterize the temporal evolution of mechanical properties, we carried out indentation tests coupled with macroscopic examinations and histological studies. This combined methodology yielded a range of information on osteogenesis at different scales: macroscopic by simple observation, mesoscopic by indentation test and microscopic by histological study. Results allowed us to identify different periods, providing a link between biological changes and material property evolution in bone tissue regeneration. The regenerated tissue evolves from a viscous, homogeneous, soft material to a heterogeneous stiffer material endowed with a lower viscosity. From a biological point of view, cell organization progresses from a proliferated cell clot to a mature structure closer to that of the bone. During the first seven days, mechanical and biological results revealed the same evolution: first, the regenerated tissue grew, then, differentiated into an osteochondral tissue and finally calcification began. While our biological results confirm those of other studies, our mechanical results provide the first experimental mechanical characterization by reduced Young's modulus of such tissue.

Response to Reviewers: Comments for the Author:

Editor's comment: A revised version of the manuscript should address all the points raised by the reviewers. In addition, please let the manuscript be revised by a native speaker of English and mention all changes made.

In addition, change the title to: TEMPORAL EVOLUTION OF SKELETAL REGENERATED TISSUE: WHAT CAN MECHANICAL INVESTIGATION ADD TO BIOLOGICAL?

The heading: Discussion and Conclusions should be changed to Discussion.

There should be concluding statement of not more than 2-4 sentences at the end of the discussion. The references should be put in order according to the instructions to authors

We take into account all these remarks 
Reviewer \#1: The authors have attempted to accommodate most of the reviewer's concerns, and the paper is now more informative. For example, an engineering interpretation of the experiments has been added by developing a simple Finite Element Model of the biologic material.

This reviewer truly appreciates the efforts done by the authors, and thinks that the manuscript results to be improved in its revised version.

Reviewer \#3: Comments

The authors should improve the flow and comprehensibility of language in their manuscript. Sections that have been added in the manuscript following the initial review comments should be quite more elaborate and thoroughly edited prior to publication.

The authors have no addressed the specific comments in my initial review:

Specific Comments

1. Pg 3. last par. ..and closer.. appears twice

2. pg 41 par ....from its genesis..

3. pg 4 last sentence. Rephrase

4. pg 5 1st par. Rephrase

5. pg par 2.1 replace undimensional with non dimensional

6. pg 13 last par. ..not included in current .. (add word in)

7. Fig. 3 add $y$-axis title

9. Fig. add y-axis title

We take into account all these remarks

8. Fig. 5 discuss the significance of the presence of negative normal load in the indentation cycle in the results- discussion sections of the manuscript

The presence of negative normal load is described in the results $\mathrm{p} 9$ "Under all experimental conditions, adhesion force never exceeds $1 \mathrm{mN}$, with no negative displacement when force becomes nought." 


\section{TEMPORAL EVOLUTION OF SKELETAL REGENERATED TISSUE : WHAT CAN MECHANICAL INVESTIGATION ADD TO BIOLOGICAL?}

Remy Casanova*, Didier Moukoko*, Martine Pithioux* ${ }^{*}$, Cyril Pailler-Mattéi ${ }^{* * * * * *}$, Hassan Zahouani**, Patrick

Chabrand*

*Institut des Sciences du Mouvement, Aix Marseille Université, CNRS UMR 6233 Marseille, France.

${ }^{* *}$ Université de Lyon, Ecole Centrale de Lyon, Laboratoire de Tribologie et Dynamiques des Systèmes, UMRCNRS 5513, Ecully, France

**** Université de Lyon, Faculté de Pharmacie ISPB, Laboratoire de Biophysique, Lyon F-69003, France

Corresponding author: Pithioux Martine

Institut des Sciences du Mouvement E.J.Marey, Equipe GIBO, Université de la méditerranée,

163 avenue de Luminy, case 918

13288 Marseille CEDEX 09, France.

Tel. 33491266177 Fax. 33491411691

E-mail address: remy.casanova@univmed.fr

Keywords : bone regeneration, large volume, indentation test, histology. 
Abstract. The objective here was to experimentally characterise the temporal evolution of the structural and mechanical properties of large volume immature regenerated tissues. We studied these evolving tissues from their genesis in controlled mechanical conditions. We developed an animal model based on the periosteal properties leading to unloaded regenerated skeletal tissue. To characterize the temporal evolution of mechanical properties, we carried out indentation tests coupled with macroscopic examinations and histological studies. This combined methodology yielded a range of information on osteogenesis at different scales: macroscopic by simple observation, mesoscopic by indentation test and microscopic by histological study. Results allowed us to identify different periods, providing a link between biological changes and material property evolution in bone tissue regeneration. The regenerated tissue evolves from a viscous, homogeneous, soft material to a heterogeneous stiffer material endowed with a lower viscosity. From a biological point of view, cell organization progresses from a proliferated cell clot to a mature structure closer to that of the bone. During the first seven days, mechanical and biological results revealed the same evolution: first, the regenerated tissue grew, then, differentiated into an osteochondral tissue and finally calcification began. While our biological results confirm those of other studies, our mechanical results provide the first experimental mechanical characterization by reduced Young's modulus of such tissue. 


\section{INTRODUCTION}

Today, skeletal tissue defects are treated with lengthy and difficult surgical operations, involving artificial materials or graft. A better understanding and better control of skeletal tissue production should improve medical techniques; which is why the regeneration of large bone segments is an important clinical problem in orthopaedic surgery. In medical and biological literature, it appears that the growth of skeletal tissue has been widely analyzed. During this biological process mesenchymal stem cells [7], increase as far as the tissue volume is totally filled in [26]. Thus the cells differentiate to get a remodeling mature tissue [1,3,4]. The temporal cells differentiation depends on environmental factors which are described by mechanobiology concepts [4,2], which explain mechanics influence on biological processes from the molecular level of the regenerating tissue extracellular matrix $[6,15]$ to its macroscopic morphology $[4,5,8]$.

A first in-vivo study based on periosteal properties demonstrated that it is possible to regenerate a whole bone volume after a large segmental resection in the New-Zealand rabbit [16]. Moukoko [16] produced regenerated osteocular material under almost nought mechanical load, analyzing the time sequences of the regeneration process. Preserved periosteal sleeve from the resected bone, brought mesenchymal precursor cells into the surgical bed, which led to the initiation of osteogenesis within the volume determined by bone resection $[16,17]$. In mechanics, skeletal tissue regeneration has often been studied using small regenerated volumes $[2,4,5,11,12,23]$ or volumes in distraction [10]. Concerning large volumes regeneration, some authors $[5,9,14,23]$ developed theoritical models studying mechanical properties temporal evolution of multipotent mesenchymal tissue.

These models were developed to describe the evolution of regenerated tissues and their validations were experimentally controlled only by comparison with the mature state. To the authors' knowledge, there was no experimental validation during the transitional period of transformation. Moukoko et al. [16] gave first results for 7,-14-and-21-days-old tissue obtained with mechanical traction tests and histological tests. After 14 days of maturation, results showed a mineralizing tissue whose mechanical characteristics were stiffer than those of cartilage and closer to those of bone. A 7-day-old tissue was shown by histological observations to be heterogeneous, with the cartilaginous component predominant and the mineralization process already apparent. With a tissue so little mineralized, traction tests produced very scattered results because they characterised the structural response of the regenerating tissues rather than their material properties.

Our work therefore aimed at experimentally characterizing the temporal evolution of the biological and material properties of large regenerated tissue volumes in the first 7 days, the period during which mineralization first 
appears. To do so, we studied this evolving tissue from its genesis under controlled mechanical conditions, linking biological observation and mechanical results. In this specific case of large volume regeneration, we expected to confirm existing theoretical and numerical models. We used an experimental animal model of skeletal tissue regeneration based on periosteal properties [16]. In order to characterise the stiffness of the regenerating materials and to describe their local material properties, we carried out micro-indentation tests $[13,20,24,27,28]$. Majority of these authors have developed dynamic study. In our case, we chose to realize experiments in quasi-static to analyze the global mechanical behavior of the regenerated tissue. In the early stages of the regeneration process, the soft component was predominant. . The use of mechanical and biological methods allow to determine the biomechanical properties evolution linked biological changes of this material. 


\section{MATERIALS AND METHODS}

\section{Clinical experiments.}

Clinical experiments were developed on the New-Zealand rabbits, a standard species for osteogenesis and chondrogenesis studies.

They were performed in an accredited experimental surgery laboratory of Montpellier Medical School (France). Fifteen three months old, weighing $2.5 \mathrm{~kg}$, skeletally males were used. The surgery was carried out in accordance with French laboratory animals regulations on animal care and use. A $25 \mathrm{~mm}$ bone segment was removed from the medial third of one tibial diaphysis of the rabbits. Under strict surgical aseptic conditions the medial third of one tibia was exposed via a medial approach. The periosteal sheet was incised longitudinally on the lateral side of the tibia in order to preserve its vascular connections with the saphenous bundle. The periosteum was elevated from the whole circumference of the bone segment (figure 1A). The leg length and axis were maintained by an external fixator in order to bypass the mechanical load through the regenerating tissues during the ambulation of the animals. The frame was secured to the bone with $2 \mathrm{~mm} \mathrm{~K}$.wires. These conditions ensure that the mechanical load on the zone of interest is almost nought and that the material produced will be bone [2,5]. A 25-mm-long bone segment was cut off (figure 1B), removed from the medial third of the tibia and a radial characteristic length was measured. The corresponding segment of fibula was removed at the same time. The periosteal mantel was carefully closed back over the segmental bone loss covering the edge of the bone section (figure 1C), In order to initiate the skeletal regeneration with mesenchymal precursor cells to the surgical bed, and to act as a barrier against adjacent soft tissue interposition. The skin was closed around the pins on the medial side of the hind limb (figure1D). After surgery, the ambulation of the animal was restricted to its cage. After the prescribed healing time, the fifteen rabbits were euthanized by an overdose of pentobarbital at chronological dates between 45 and 160 hours in order to analyze the regenerated tissues at different stages of maturation. We sacrificed two rabbits after about two days healing, three rabbits after about three days, five rabbits after about four days, two rabbits after about five days, one rabbit after about six days and two rabbits after about seven days. For all fifteen rabbits, the regenerated tissues were explanted and were radially cut into three $8 \mathrm{~mm}$ thick samples (figure 2A). The future indented surface was carefully generated with a scalpel. This type of material needs no more preparation. The 45 samples obtained were moulded in a polyester resin to be tested by micro-indentation (figure 2B). This precludes interaction between the studied tissue and the resin 
which does not infiltrate the regenerated material but merely maintains it. The rest of produced tissue was fixed in a Winkler solution and intended for histological study.

2. In vitro experiments.

\subsection{Macroscopic examination.}

First, observation of the samples allowed us to roughly describe the evolution of regenerated material filling the gap left by lost tissue at organ level during the first 7 days of the process. Second, we measured the mean characteristic radial length of initial bone and regenerated tissues. This length was determined from numerical photography with the free software Image J by surface measurement in the radial plane (figure $2 \mathrm{~B}$ ). We then introduced a non dimensional variable defined as the ratio between these two values in order to compare the regenerated tissue volumes produced by each animal.

\subsection{Histology.}

A conventional histological study of the samples was performed on the regenerated tissue. After the medical healing time, the regenerate was fixed in a Winkler solution, tested by micro-indentation and embedded in paraffine. Decalcification was performed on the samples that were mineralised. Samples were cut transversely and Hematoxylin-Eosin-Saffron (HES) stain was used. Microscope observation was used to analyze changes in cell type and organization over healing time.

\subsection{Micro-indentation}

A micro-indentation test was used to describe the mechanical material properties of the regenerated tissue. (figure 3A). Loading-unloading indentation cycles were performed with a pre-defined maximum normal force of between 20 -and $100 \mathrm{mN} \pm 0.2 \mathrm{mN}$. We chose a spherical ruby indenter with a radius of curvature of $1 \mathrm{~mm}$. We chose to use a spherical indenter for two raisons:

-first the contact area was more important with this indenter than with a conical one. The strain imposed on the material was less important with this kind of indenter. So we analyzed more precisely the elastic behavior of the tissue.

-second, the conical indenter allowed to analyze the viscoelastoplastic behavior of the tissue because the material rapidly plasticized and we were not interested about this.

The indentation device was controlled by a fixed constant displacement velocity of between 20 and $500 \pm 1 \mu \mathrm{m} / \mathrm{s}$. We continuously measured normal force variation as a function of material penetration depth. Two or three points were tested on each specimen on the more mature part of the tissue (figure 2B). At each point, a standard test was performed with four identical loading/unloading cycles characterized by a $40 \mathrm{mN}$ maximum normal 
force and a $50 \mu \mathrm{m} / \mathrm{s}$ displacement velocity. At a second stage, on each sample, and for only one point, we performed indentation with various normal forces: $20 \mathrm{mN}, 40 \mathrm{mN}, 60 \mathrm{mN}, 80 \mathrm{mN}$ and $100 \mathrm{mN}$ and various displacement velocities: $20, \mu \mathrm{m} / \mathrm{s}, 50 \mu \mathrm{m} / \mathrm{s}, 100 \mu \mathrm{m} / \mathrm{s}, 200 \mu \mathrm{m} / \mathrm{s}$ and $500 \mu \mathrm{m} / \mathrm{s}$. For these indentation tests, we calculated the reduced Young's modulus. This parameter is obtained from the Hertz theory, which considers a contact between an undeformable smooth spherical ruby indenter and a smooth elastic flat substrate. The main assumptions of Hertz's theory are the following: solids are subjected to low strain under the elastic limit; there is no sliding or adhesion between surfaces and contact dimensions are small compared to radii of curvature of both surfaces. Under these conditions, the relationship between depth, $\delta$ and the normal load, Fn is given by (1) where $\mathrm{R}$ is the indenter radius and $\mathrm{E}^{*}$ the reduced Young's modulus of the substrate given by (2) with E, Young's modulus and $v$, Poisson ratio of the substrate $[18,19,22]$.

$$
\begin{aligned}
& \text { (1) } F n=\frac{4}{3} \cdot E^{*} \cdot \sqrt{R} \cdot \delta^{\frac{3}{2}} \\
& \text { (2) } E^{*}=\frac{E}{1-v^{2}} \\
& \text { (3) } E^{*}=\frac{3}{4} \cdot F n_{M A X} \cdot \sqrt{R} \cdot \delta_{M A X}^{\frac{2}{3}}
\end{aligned}
$$

E* parameters are calculated for each test considering the maximum normal force $\mathrm{Fn}_{\mathrm{MAX}}$ and the maximum depth $\delta_{\text {MAX }}$ (3). In order to validate our experimental protocol, an indentation test was performed on a homogenous, isotropic and elastic, silicone elastomer with a known reduced Young’s modulus $(2 \pm 0,1 \mathrm{MPa})$ calculated with a nano-indenter (XP® MTS). With micro-indentation, we obtained the same value with the same calculation error. This device was also validated on biological material like the skin [20, 21].

In order to validate our calculation of the reduced Young's modulus, we developed a finite element model with ABAQUS. We simulated a numerical indentation test. We have run these numerical simulations on a semiinfinite medium [20, 21, 28]. The indenter was assumed to be rigid. The contact between the indenter and the regenerate may have been treated as a simple sphere-plane contact which makes calculations possible with an axisymmetrical option (figure 3B). The mass inertial effects have been neglected and four-node quadrangle elements have been used. The spatial and temporal dimensions used were the same of the experimental ones (figure $3 \mathrm{~A}, \mathrm{~B}$ ). The regenerate is a visco-elastic deformable middle. In the model, elasticity is defined with a Young modulus $\mathrm{E}_{0}$, a Poisson coefficient $v_{0}$. Viscosity is defined with a Zener model defined by a viscosity rate $\% \mathrm{E}_{1}$ and a relaxation time $\tau_{1}$. The behavior of the material follows the equation (4): 
(4) $E(t)=E_{0}\left(1-\% E_{1}\left(1-e^{\frac{-t}{\tau_{1}}}\right)\right)$ 


\section{RESULTS}

1. Macroscopic and histological results.

Figure 4 shows, the temporal evolution of the ratio between the regenerated tissue characteristic radial length and that of the excised bone segment. Several stages are revealed over two periods. First, the ratio increased from 0.93 to 1.39 with an increment of 0.26 per day, during the first 80 hours, including day 3 . Then the expansion of regenerated tissue stopped. In the second period, from day 5 to day 7, the ratio remained almost constant at about 1.39 with a standard deviation $\sigma=0.09$.

Figure 5 shows macroscopic observations on a transverse section of regenerated tissue as it changed throughout the study period and the histological results for the area of mechanical tests, concentrating on the most mature part. The regenerated tissue, observed by macroscopic examination, varies in appearance over the study period. At day three (figure 5A), the macroscopic regenerate took on a cylindrical appearance with a homogeneous, soft, rubbery consistency. At day five (figure 5B), tissue organization had assumed a heterogeneous appearance with a crown structure. The periphery had a stiffer consistency and irregular thickness. The center remained more or less identical. At day seven (figure 5C), the crown organization persisted and the cylindrical appearance became more marked with a peripheral crown that was thicker and more and more mature. The center of the sample remained softer and less differentiated.

At day three (figure 5), a massive cellular proliferation filled the tissue gap with mesenchymal cells. There condensation was organized like an anlage, a precursor of the future cylindrical morphology of the regenerate. Peripheral tissue matured faster than the center of the regenerate which hosted immature cells. By day 5 (figure 5B), the peripheral ring was composed of tissue progressively achieving a cartilaginous phenotype. The chondroblasts synthesized an abundant extra cellular matrix. At day 7 (figure 5C), a gradual enchondral ossification of the periphery occurred. A mineralization front imitating trabeculae appeared within hypertrophic chondrocyte giving a heterogeneous appearance to the peripheral tissue, predominantly cartilaginous.

\section{Mechanical results.}

All the indentation tests were carried out on peripheral tissue where the material was the most mature. The extremal indentation depths were $40 \mu \mathrm{m}$ and $560 \mu \mathrm{m}$. All tests revealed similar overall shapes of the curves. It can be observed from figure 6 that adhesion of the indenter on the substrate is very low. Under all experimental conditions, adhesion force never exceeds $1 \mathrm{mN}$, with no negative displacement when force becomes nought. The loading and unloading curves mark the boundaries of a hysteresis area corresponding to the dissipated work 
(figure 6). The elastic work may be measured under the unloading curves. Numerical simulations have shown that dissipated work may be modelled in main part by viscous effects (figure 7). For each single measurement point, all the curves obtained with each of the same four loading/unloading cycles were more or less identical (figure 6). As the maximum depths are similar, calculation of the reduced Young's modulus $E^{*}$ from equation 3 gives a standard deviation lower than $5 \%$ in $85 \%$ of the calculated values. The unloaded material state was the same before and after the test under each loading condition, in terms of displacement velocity and maximum normal forces. This means that there is no irreversible deformation and therefore no plastic effects, validating the choice of small strain under the elastic limit. At the maximum loading point, the slopes of the loading and unloading curves are different and the calculation of $\mathrm{E}^{*}$ with different maximum normal force or different displacement velocity did not produce acceptable results. For this reason, we did not use the Oliver-Pharr method with this material $[18,19,22]$. On the other hand, loading behaviour approaches that of a perfect elastic material (figure 7). Its variations with different maximum forces $(20 \mathrm{~N}, 40 \mathrm{~N}, 60 \mathrm{~N}, 80 \mathrm{~N}$ and $100 \mathrm{~N})$ are minimal and the curve reveals the same evolution (figure 7). Considering the maximal normal force variation to calculate the $E^{*}$ (equ 3), the standard deviation of $E^{*}$ is lower than $15 \%$ for $87 \%$ of the tests (figure 7 ). However, numerical tests confirm that viscosity does not influence the calculation of $\mathrm{E}^{*}$ if the viscous parameters $\% \mathrm{E}_{1}$ and $\tau_{1}$ are not too high. In this case, the hysteresis of the curve is not very important. When $\% \mathrm{E} 1$ is less than $50 \%$, the $\mathrm{E}^{*}$ calculation error is less than $15 \%$, with Fnmax between $20 \mathrm{mN}$ and $100 \mathrm{mN}$ (figure 7).

Figure 8 shows the temporal evolution of the reduced Young's modulus. Each date corresponds to one sacrificed animal from which 3 samples were obtained. On each sample, indentation was carried out at 1,2 or 3 points depending on the size of the available material (figure 2B). This is the reason why there are between 5 and 9 values per animal (figure 8 black point $\bullet$ ). Considering the hydratation condition, our micro-indentation study curves results showed that there was no adhesion effect. In our experimental study, there was no capillarity effect showing that water did not get out of the materials.

To evaluate the $\mathrm{E}^{*}$ variation with healing time, we grouped together the rabbits by healing day (figure 8 grey line-). During the first 7 days, the results show several sequences over two periods. Before 100 hours, including day $3, \mathrm{E}^{*}$ is almost constant and homogeneous. The $\mathrm{E}^{*}$ average is about $0.31 \mathrm{MPa}$ with a standard deviation of 0.23. In the second period, after 100 hours, including day 5 and day $7 \mathrm{E}^{*}$ is stiffer than in the first, with more scattered results. The reduced Young modulus average is about $0.91 \mathrm{MPa}$ with a standard deviation of 0.83 .

The variations in $\mathrm{E}^{*}$ according to the displacement velocity are greater. $\mathrm{E}^{*}$ increases with velocity. With a $20 \pm 1 \mu \mathrm{m} / \mathrm{s}$ displacement velocity, $\mathrm{E}^{*}$ are $7.9 \%$ lower than with $50 \pm 1 \mu \mathrm{m} / \mathrm{s}$; when the displacement velocity is 
$100 \pm 1 \mu \mathrm{m} / \mathrm{s}$, they are $8.9 \%$ stiffer. With $200 \pm 1 \mu \mathrm{m} / \mathrm{s}$ and $500 \pm 1 \mu \mathrm{m} / \mathrm{s}$ displacement velocities, the variations in $\mathrm{E}^{*}$ are greater than $20 \%$. For each displacement velocity, we introduced a variable $\Delta \mathrm{E}(\mathrm{i})$ given by equation 4 to evaluate the effect of velocity displacement on the $\mathrm{E}^{*}$ calculation.

$$
\text { (5) } \Delta E(i)=\frac{E^{*}(i)-E^{*}(50)}{E^{*}(50)}
$$

In (5) $\mathrm{E}^{*}(\mathrm{i})$ indicates the reduced Young's modulus calculated for velocity i. Figure 9 shows various values of $\Delta \mathrm{E}$ (i) for $\mathrm{i}=(20,100,200$ and $500 \pm 1 \mu \mathrm{m} / \mathrm{s})$ as functions of healing time. The material is more viscous before 100 hours than after. With a $500 \pm 1 \mu \mathrm{m} / \mathrm{s}$ displacement velocity, the reduced Young modulus variation average is $39 \%$, for tissue maturity of less than 100 hours, falling to $18 \%$ after 100 hours. For day 7 , the effect of velocity seems to increase further. This result is confirmed by calculating viscous work and elastic work. When we calculated the viscous work percentage compared to the total work, we realized that this one decreased with the maturation age of the regenerate (figure 9). In the two first days, this ratio was about $48 \%$, for day 4 and 5 , about $42 \%$ and for days 6 and 7 about $39 \%$. 


\section{DISCUSSION}

In our model, we used a combination of macroscopic observations, histology and indentation to link various observation scales on describing osteogenesis in its earlier phases. This revealed that, during these premature periods, several stages of development can be distinguished.

-The first period corresponds to the expansion of the regenerated tissue, when the ratio between the initial bone radius and the regenerated tissue radius increases continuously. The overall geometry of the regenerated segment is thus still evolving [16]. This is in good agreement with the histology analysis which showed a massive cellular proliferation. Mechanically, elastic properties are relatively constant with a reduced Young modulus about 0.35 $\mathrm{MPa}$ and viscous properties are extensive. This material is softer than cartilage [24,25].

-In the second period, from about day four, the volume of the regenerate reaches a stable state. The tissue organization assumes a heterogeneous structure with two different circular phases, the external phase being more mature than that at the center and the cell phenotype maturing towards osteochondral lineage. Mechanical properties are close to those of cartilage with a reduced Young's modulus between 0.5 and 2.5MPa [24,25]. In this period, the viscous effects decrease with healing time.

-During the third period, from about day five, calcification trabeculae-like appears, with sparse distribution. For a single sample, the results depend on the indentation point. The mineralization rate is not homogeneous in the overall external crown. The reduced Young modulus measurement depends of the indentation point. Some results keep the same value than cartilage, other one are stiffer. This explains the greater scattering of results in this material whose stiffness increases whereas the viscous effect decreases.

Inherent to work on living tissue there are individual physiological differences explaining the scattering in results over time. Each rabbit has its own speed of recovery which explains the dependence of the results on evaluation dates. However, the mechanical properties of the regenerate follow the same temporal evolution.

During the three periods identified, the regenerate evolves from a viscous homogeneous soft material to a heterogeneous stiffer material endowed with a lower viscosity. From a biological point of view, cell organization assumes a mature structure closer to that of bone.

From a mechanical point of view, this study confirms the local tissue property evolution data already published [14]. However, at organ level, we observe that tissue does not always evolve identically for the same mechanical load. Tissue organization and tissue maturation differ according to their location. The center and the peripheral 
crowns do not mature at the same rate. Moreover, within an identical area, calcification does not begin in an homogenous way and begins at certain points before the entire organ hardens. These aspects of development are not included in current theoretical models of bone regeneration based on homogeneous simplifications [14].

In conclusion, our model clearly makes it possible to describe biological changes and inherent mechanical properties in the very early stages of bone tissue regeneration. Thus, our methodology yields a range of informations on osteogenesis at different scales. Indentation tests coupled with histological studies and macroscopic observations provide a link between biological changes and material property evolution in bone tissue regeneration. While our biological results confirm those of other studies $[1,3,5,26]$, our mechanical results provide the first experimental mechanical characterization by reduced young's modulus of such a tissue. To obtain classic Young modulus, Poisson ratio value from literature exists for osteoarticular material about 0.3 to $0.45[24,25]$. But there is no value for regenerated bone. Using finite element modelling, with different material properties like viscoelastic or poroelastic behaviour, we may identify more material characteristics. Other experimental studies like ultrasound can be developed to analyze the Poisson ratio for example. 


\section{References}

1. Buckwalter JA, Glimcher MJ, Cooper RR, Recker R (1995) Bone Biology. Journal of bone and Joint Surgery $77: 1276-1289$

2. Claes LE, Heigele CA (1999) Magnitudes of local stress and strain along bony surfaces predict the course and type of fracture healing. Journal of Biomechanics 32:255-266

3. Caplan AI (1994) The mesengenic process. Clinics in Plastic Surgery 21:429-435

4. Carter DR, Blenman PR, Beaupre GS (1988) Correlations between mechanical stress history and tissue differentiation in initial fracture healing. Journal of Orthopaedic Research 6:736-748

5. Carter DR, Beaupre GS, Giori NJ, Helms JA (1998) Mechanobiology of skeletal regeneration. Clinical Orthopaedics and Related Research 355S:S41-S55

6. Cullinane DM, Salisbury KT, Alkhiary Y, Eisenberg S, Gerstenfeld L, Einhorn TA (2003) Effects of the local mechanical environment on vertebrate tissue differentiation during repair: does repair recapitulate development? Journal of Experimental Biology 206:2459-2471

7. Ferguson C, Alpern E, Miclau T, Helms JA (1999) Does adult fracture repair recapitulate embryonic skeletal formation? Mechanisms of development 87:57-66

8. Heegaar JH, Beaupre GS, Carter D (1999) Mechanically modulated cartilage growth may regulate joint surface morphogenesis. Journal of Orthopaedic Research 17:509-517

9. Huiskes, R., Driel, W.D., Prendergast, P.J., Soballe, K., 1997. A biomechanical regulatory model for periprosthetic fibrous-tissue differentiation. Journal of Materials Science: Materials in Medicine 8:785-788.

10. Isaksson H, Comas O, Van Donkelaar CC, Mediavilla J, Wilson W, Huiskes R, Itoa K (2007) Bone regeneration during distraction osteogenesis: Mechano-regulation by shear strain and fluid velocity. Journal of Biomechanics 40:2002-2011

11. Lacroix D, Prendergast PJ (2002) A mechano-regulation model for tissue differentiation during fracture healing: analysis of gap size and loading. Journal of Biomechanics 35:1163-1171

12. Lacroix D, Prendergast PJ, Li G, Marsh D (2002) Biomechanical model to simulate tissue differentiation and bone regeneration: application to fracture healing. Medical \& Biological Engineering \& Computing 40:14-21

13. Lau A, Oyen ML, Kent RW, Murakami D, Torigaki (2008) Indentation stiffness of aging human costal cartilage. Acta Biomaterialia 4(1):97-103

14. Loboa EG, Wren TA, Beaupre GS, Carter DR (2003) Mechanobiology of soft skeletal tissue differentiationa computational approach of a fiber-reinforced poroelastic model based on homogeneous and isotropic simplifications. Biomechanics and Modeling in Mechanobiology 2:83-96

15. Mikic B, Isenstein AL, Chhabra A (2004) Mechanical modulation of cartilage structure and function during embryogenesis in the chick. Annals of Biomedical Engineering 32:18-2.

16. Moukoko D, Pithioux M, Chabrand P (2007) Temporal evolution of mechanical properties of skeletal tissue regeneration in rabbits: an experimental study. Medical and Biological Engineering and Computing 45:989-995

17. O'Driscoll SW, Fitzsimmons JS (2001) The role of periosteum in cartilage repair. Clinical Orthopaedics and Related Research 391 Suppl:S190-S207

18. Oliver WC, Pharr GM. (1992) An improved technique for determining hardness and elastic modulus using load and displacement sensing indentation experiments. Journal of Material Research 7(6):1564-83

19. Oliver WC, Pharr GM. (2004) Measurement of hardness and elastic modulus by instrumented indentation: advances in understanding and refinements to methodology. Journal of Material Research 19(1):3-20 
20. Pailler-Mattéi C, Zahouani H (2006) Analysis of adhesive behaviour of human skin in vivo by an indentation test. Tribology International 39:12-21

21. Pailler-Mattei C, Bec S, Zahouani H (2008) In vivo measurements of the elastic mechanical properties of human skin by indentation tests Medical Engineering \& Physics, 30:599-606

22. Pharr GM, Oliver WC, Brotzen FR (1992) On the Generality of the Relationship Between Contact Stiffness, Contact Area, and Elastic Moduli During Indentation. Journal of Materials Research 7:613-617

23. Prendergast PJ, Huiskes R, Soballe K (1997) ESB Research Award 1996, Biophysical stimuli on cells during tissue differentiation at implant interfaces. Journal of Biomechanics 30:539-548

24. Räsänen T, Messner K (1996) Regional variations of indentation stiffness and thickness of normal rabbit knee articular cartilage. Journal of Biomedical Materials Research 31:519-524

25. Roemhildt ML, Coughlin KM, Peura GD, Fleming BD, Beynnon BD (2006) Material properties of articular cartilage in the rabbit tibial plateau. Journal of Biomechanics 39:2331-2337

26. Simon T.M, Van Sickle DC, Kunishima DH, Jackson DW (2003) Cambium cell stimulation from surgical release of the periosteum. Journal of Orthopaedic Research 21:470-480

27. Soons JAM, Aernouts J, Dirckx JJJ (2009) Elasticity modulus of rabbit middle ear ossicles determined by a novel micro-indentation technique. Hearing Research (in press)

28. Zhang J, Niebur GL, Ovaert TC (2008) Mechanical property determination of bone through nano- and microindentation testing and finite element simulation. Journal of Biomechanics 41(2):267-275 
Figure 1 A, B, C, D.

The four most important steps in the clinical experiment with relevation of periosteal mantel (A), $25 \mathrm{~mm}$ bone segment resection (B), closure of periosteum and other membrane (C) and finally, external fixator (D).

\section{Figure 2 A, B}

(A) Appearance of explanted tissue after 7 days healing and diagram of cut direction. (B) Example of seven days healing time sample ready for indentation with numerically marked area of regenerated volume (yellow line - ) and three points of indentation (blue point $\bullet$ )

\section{Figure $3 \mathrm{~A}, \mathrm{~B}$,}

Desciption of experimental indentation test and typical finite-element mesh, composed of axisymmetric fournode quadrangle elements and rigid spherical indenter

\section{Figure 4}

Evolution over healing time of the ratio between the regenerated tissue characteristic radial length and that of the initial bone segment.

Figure 5 A, B, C

Macroscopic and histological view of regenerating tissues after healing time of 3 days (A), 5 days (B) and 7 days (C).

Figure 6

Example of four indentation cycles of loading-unloading on 86 hours old regenerated tissue.

Figure 7

Indentation on 157 hours old regenerated tissue with a displacement velocity of $50 \mu \mathrm{m} / \mathrm{s}$ and successive maximum normal force of $20 \mathrm{mN}, 40 \mathrm{mN}, 60 \mathrm{mN}, 80 \mathrm{mN}$ and $100 \mathrm{mN}$ and simulation of indentation with theoritical hertz model and viscoelastic numerical model in the same condition.

Figure 8.

Reduced Young's modulus calculated for each point of indentation as a function of healing time. Daily evolution of the regenerated tissue reduced Young's modulus.

\section{Figure 9}

Evolution of pourcent of viscous work on total work and of $\Delta \mathrm{E}(\mathrm{i})$ for $\mathrm{i}=(20,100,200$ and $500 \pm 1 \mu \mathrm{m} / \mathrm{s})$ as functions of healing time 
Figure $1 \mathrm{~A}, \mathrm{~B}, \mathrm{C}, \mathrm{D}$

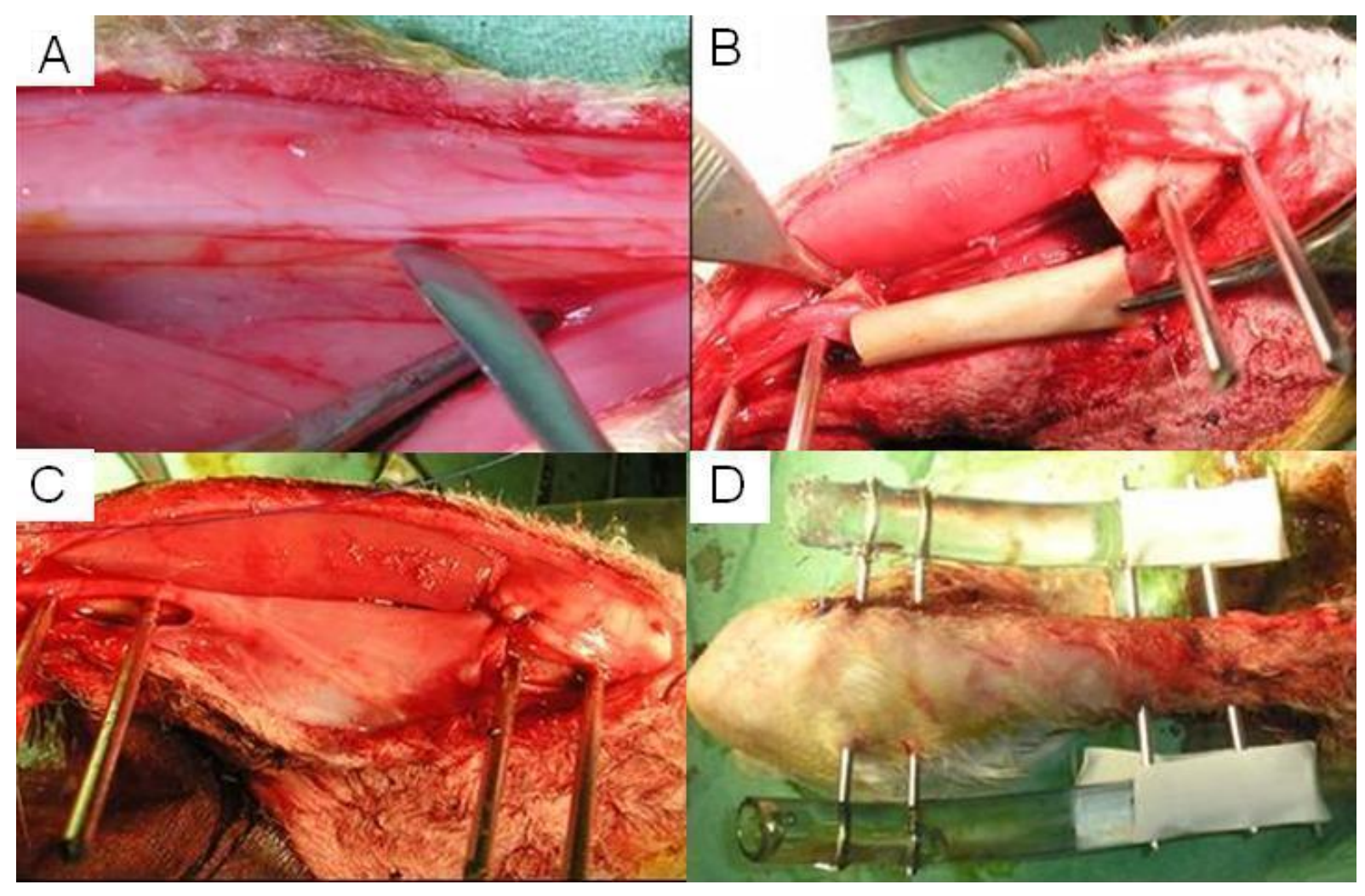


Figure 2 A, B

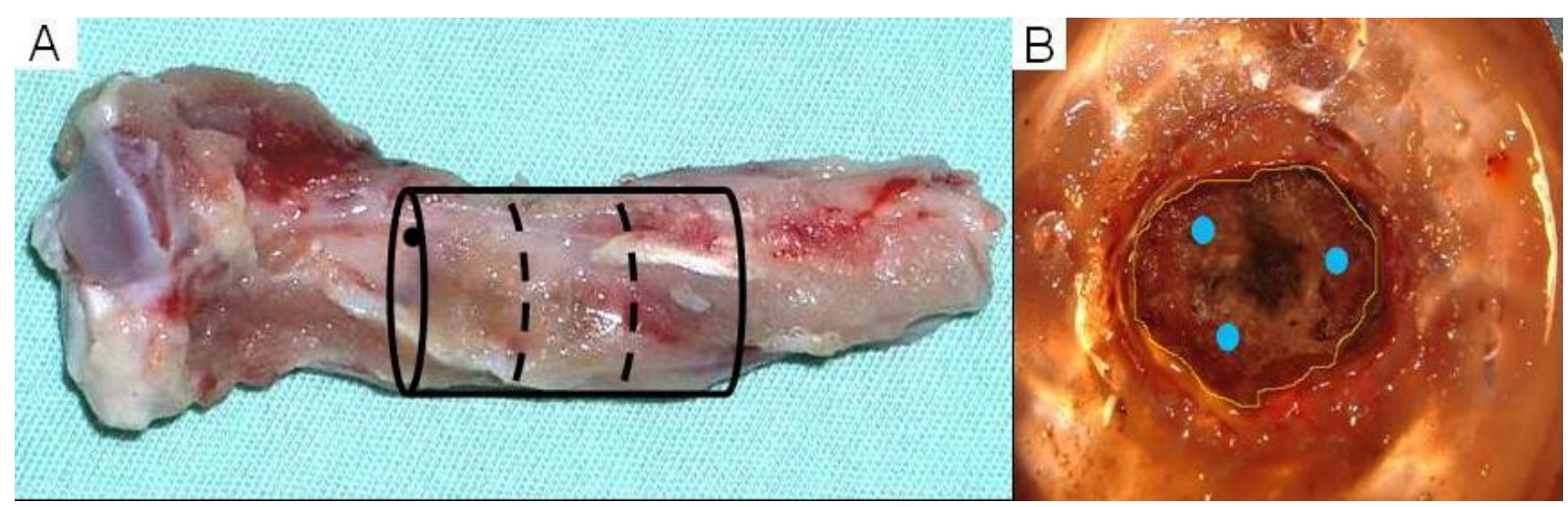


Figure 3 A, B.

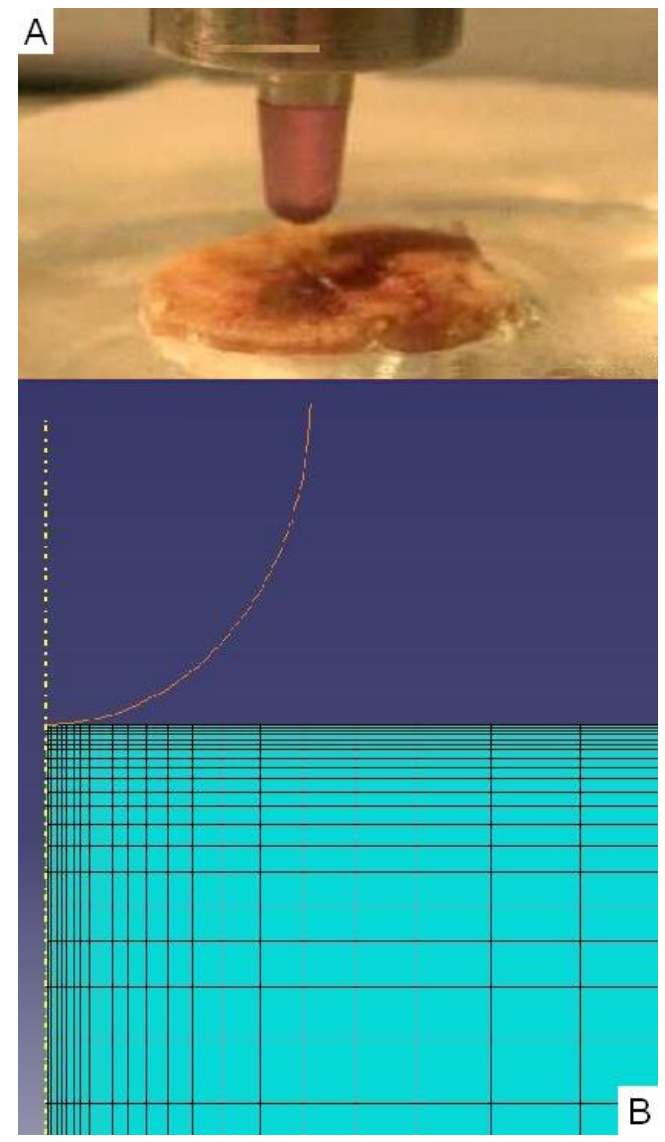


Figure 4

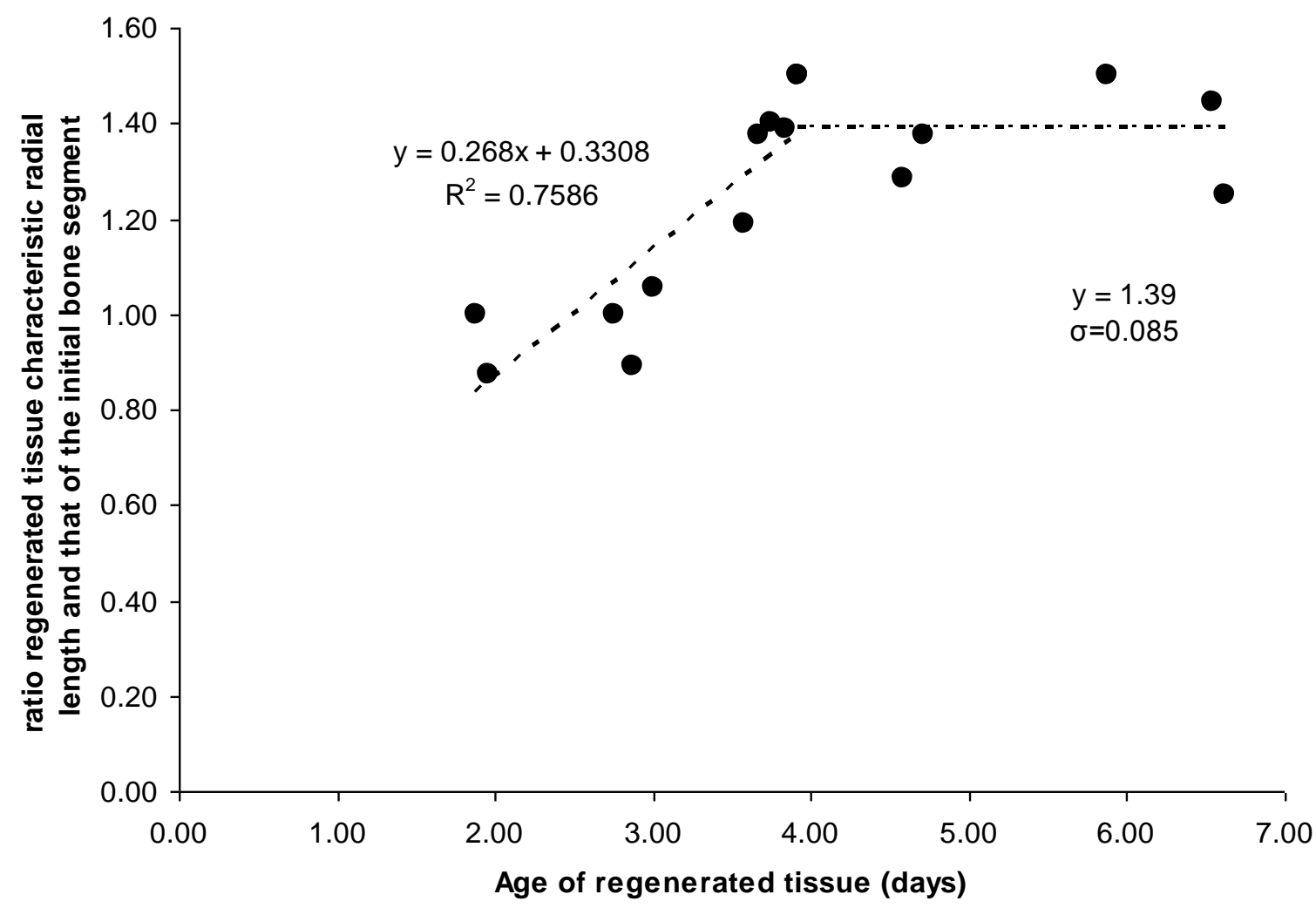


Figure 5 A, B, C.
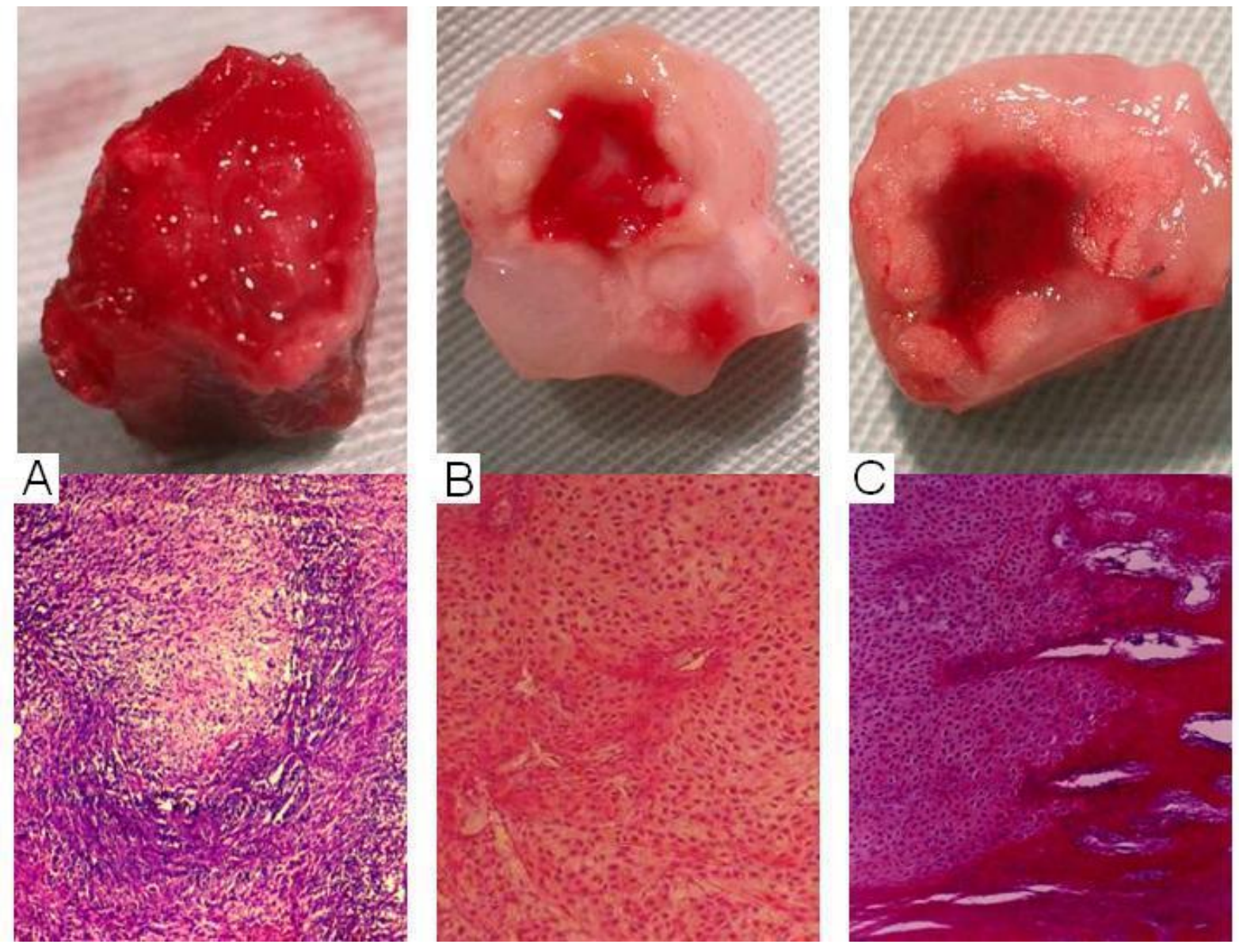
Figure 6

Four indentations on 86 hours old regenerat

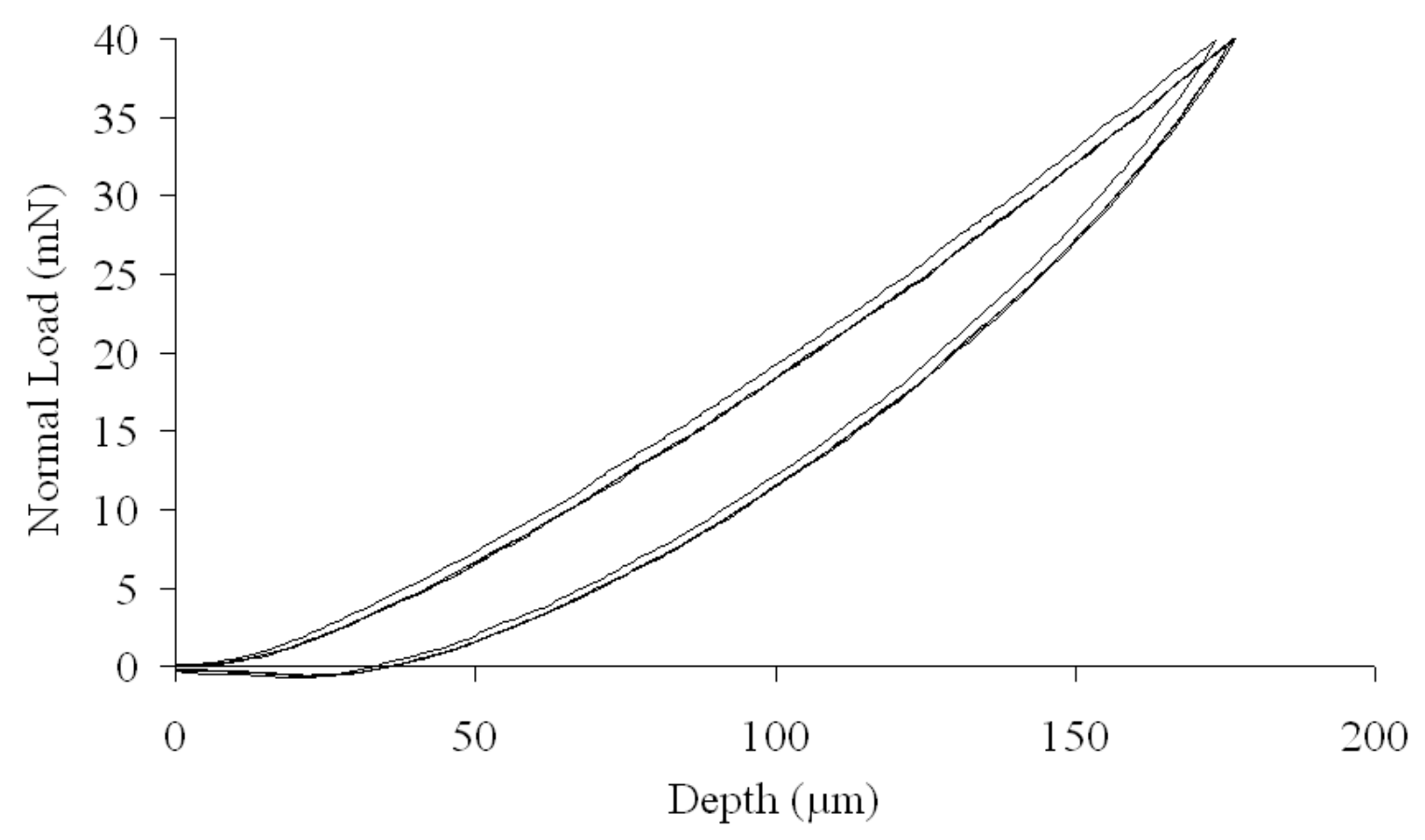


Figure 7

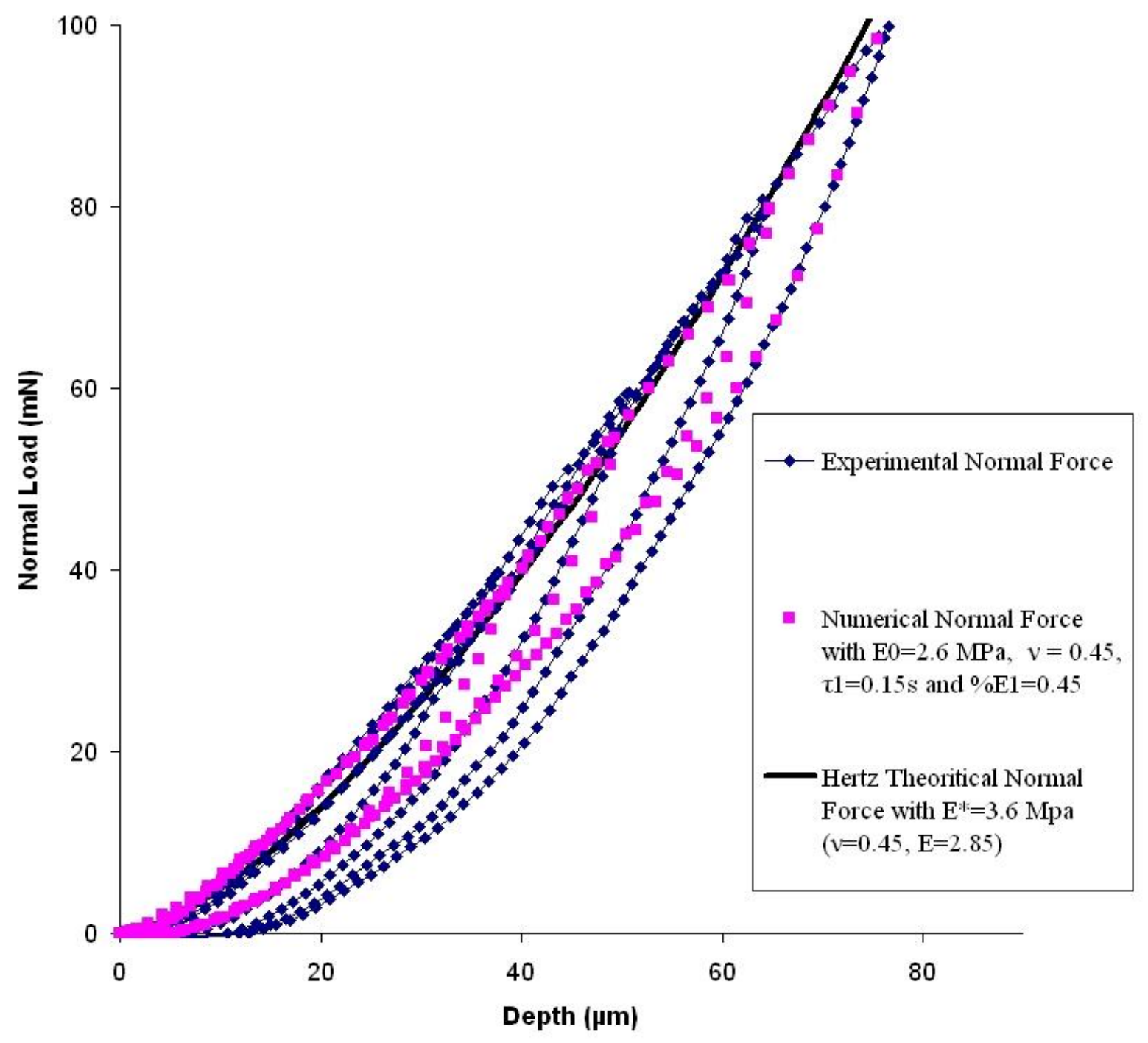


Figure 8.

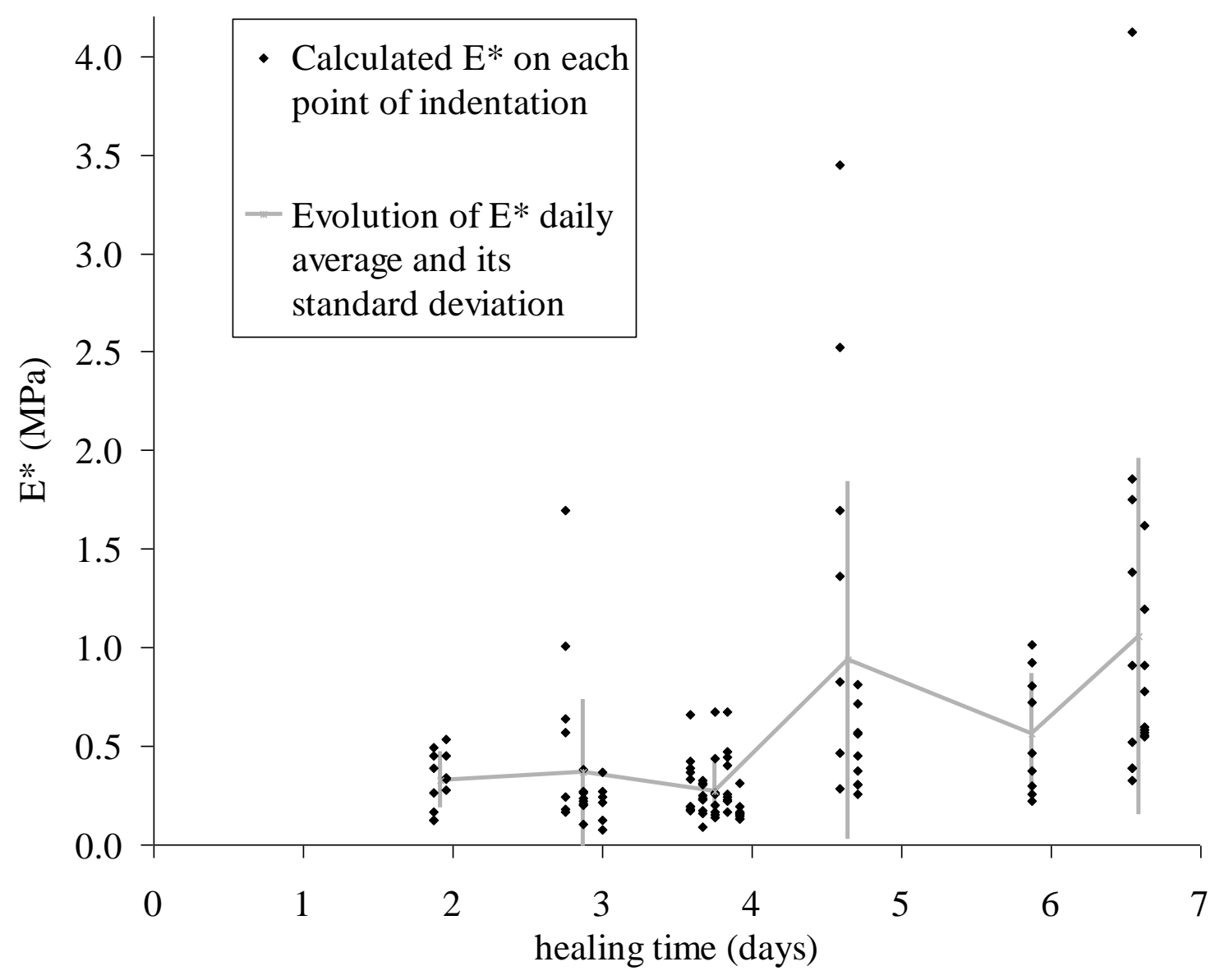


Figure 9.

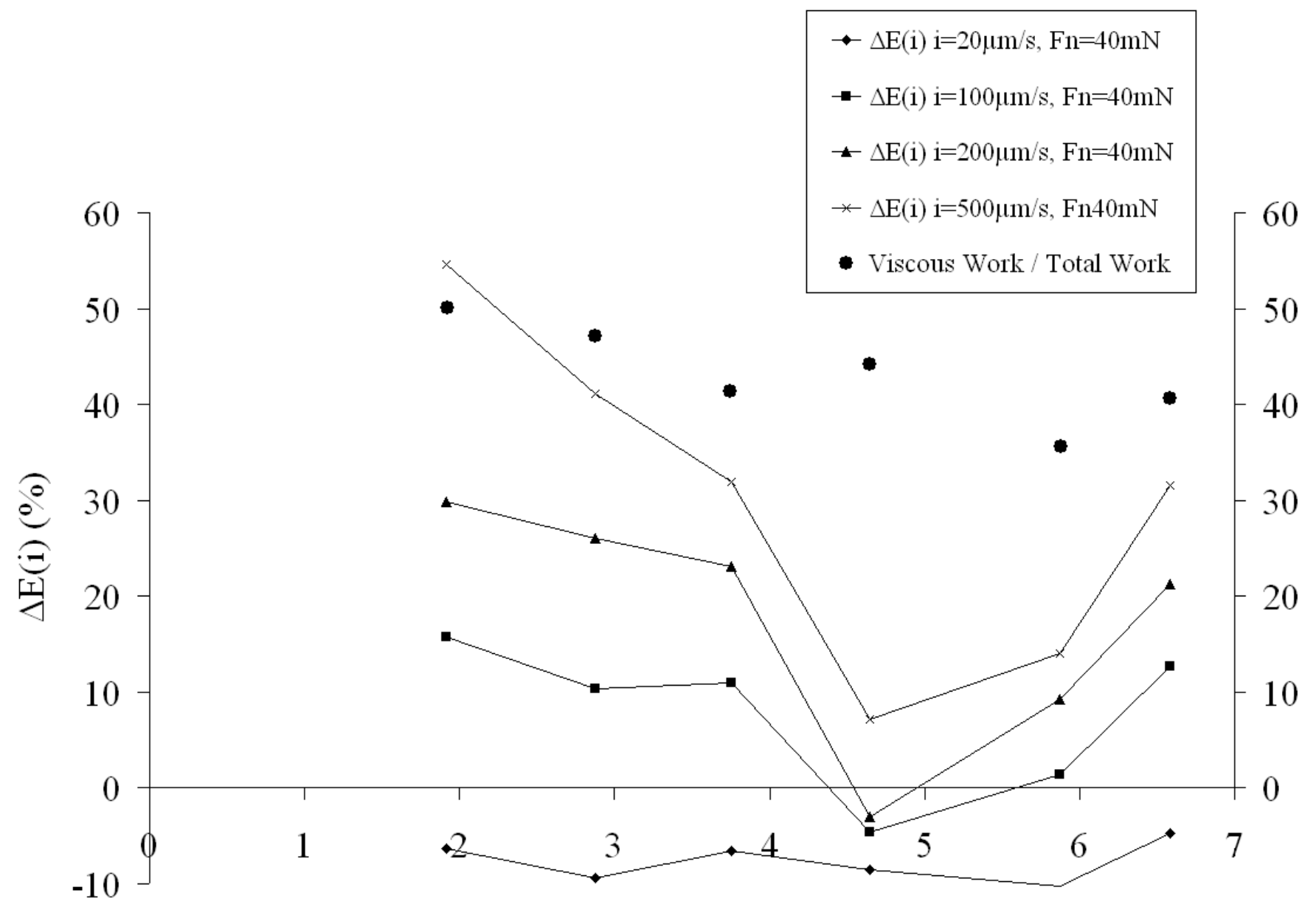

Age of regenerated tissue (days). 